\title{
Subjetividad y tecnologias de la escritura. La formación en tiempos de poshumanismo ${ }^{1}$
}

\author{
Rocio Rueda Ortiz ${ }^{2}$ \\ Universidad Pedagógica Nacional, Bogotá, Colombia \\ rrueda@pedagogica.edu.co \\ Recibido: 22 de enero de 2016 \\ Aceptado: 22 de julio de 2016 \\ Disponible en línea: 20 de diciembre de 2016
}

1 Se trata de un artículo de reflexión que retoma los resultados de la investigación finalizada "Formas de presentación de la persona en la red social Facebook", realizada entre 2011 y 2013, para analizarlos de manera crítica a la luz de la pregunta por la formación en tiempos de poshumanismo. Para ello se establece un diálogo con autores críticos contemporáneos y con la información proveniente del trabajo de campo cualitativo del estudio antes mencionado (especialmente entrevistas y registros de la etnografía virtual en la red social Facebook). Finalmente se presentan unas consideraciones sobre cómo pensar la pedagogía hoy como una artesanía. La investigación fue coordinada y financiada principalmente desde la Universidad del Valle (Código 5232). Adicionalmente, contó con la cooperación interinstitucional de la Universidad Pedagógica Nacional y la Universidad ICESI.

2 Doctora en Educación, Universidad de las Islas Baleares (España). Profesora catedrática, Doctorado Interinstitucional en Educación, Universidad Pedagógica Nacional (Bogotá, Colombia). 


\title{
Subjetividad y tecnologias de la escritura. La formación en tiempos de poshumanismo
}

\section{Resumen}

Este artículo se sustenta en una investigación cualitativa sobre los procesos de formación subjetiva en las redes sociales digitales. Se parte de una cuestión filosófica fundamental: la formación humana en medio de un mundo altamente tecnologizado. En la primera parte se expone brevemente el marco conceptual desde la relación formación-pedagogia-escritura(s), los estudios sociales de ciencia y tecnología y de cultura material, que nos permiten hablar de "tiempos de poshumanismo". En la segunda, se describen los mecanismos de co-formación en las nuevas formas de socialidad plataformada en la red social Facebook: programabilidad, popularidad, conectividad y dataficación, donde la agencia de humanos y no humanos se pone en juego y donde se producen paradójicos procesos informales de formación individual y colectiva. Esta nueva condición lleva, en la tercera parte, a retomar la noción de formación como artesanía en tiempos de poshumanismo.

Palabras clave: subjetividad; formación; escrituras; tecnologias; poshumanismo

\section{Subjectivity and Writing Technologies. Training in the Time of Posthumanism}

\begin{abstract}
This paper is based on a qualitative research on subjective training processes in digital social networks. It starts with a fundamental philosophical question: human training in the midst of a highly technological world. The first part briefly explains the conceptual framework from the training-teaching-writing(s) relationship, social studies of science and technology and of material culture, that allow us to speak of the "time of posthumanism." The second part describes the co-training mechanisms in the new forms of social interaction through technology platforms in the social network Facebook: programmability, popularity, connectivity, and datification, where the agency of humans and non-humans is at stake and where paradoxical informal processes of individual and collective training occur. This new condition leads, in the third part, to revisit the notion of training as a craft in the time of posthumanism.
\end{abstract}

Keywords: subjectivity; training; scriptures; technologies; posthumanism

\section{Subjetividade e tecnologias da escrita. A formação em tempos de pós-humanismo}

\section{Resumo}

Este artigo é baseado em uma pesquisa qualitativa sobre processos de formação subjetiva nas redes sociais digitais. Parte de uma questão filosófica fundamental: a formação humana no meio de um mundo altamente tecnologizado. Na primeira parte expõe brevemente o quadro conceitual desde a relação formação-pedagogia-escrita(s), os estudos sociais de ciência e tecnologia e de cultura material, que permitem nos falarmos de "tempos de posthumanismo". Na segunda, são descritos os mecanismos de co-formação nas novas formas de socialidade plataformada na rede social Facebook: programabilidade, popularidade, conectividade e dadaficação, onde a agencia de humanos e não humanos é posta em jogo e onde se produzem paradoxais processos informais de formação individual e coletiva. Tal nova condição leva, na terceira parte, para retomar a noção de formação como artesanato em tempos de pós-humanismo.

Palavras-chave: subjetividade; formação; escritas; tecnologias; pós-humanismo 


\section{Formación y (nuevas) tecnologias de la escritura}

La formación se orienta tanto al sujeto (en lo que puede y quiere llegar a ser), como a la cultura (su reproducción y transformación). Este ha sido el objeto de la pedagogía moderna y su institución central, la escuela. La formación se concibió como instrucción, adiestramiento y humanización en el contexto de un proyecto científico y cultural civilizatorio, de configuración de naciones y democratización de las sociedades. El libro y la escritura fueron los dispositivos de formación tanto para la construcción de la experiencia de sí, sustentada en la razón y las ciencias, como para la educación ciudadana y la participación política (Sting, 1998). Hoy el proyecto de la modernidad, aún incompleto, enfrenta críticas severas por los desmanes de la ciencia y la tecnología, la barbarie de las guerras mundiales y los daños ambientales (Sloterdijk, 2000). Por un lado, la experiencia de sí y de vida compartida desborda aquella idea de formación instruccional e institucional. Los sujetos (desde la infancia y la juventud) buscan hacerse por sí mismos, formarse, diferenciarse, lograr reconocimiento no solo en la escuela, sino a través de diversas experiencias en la ciudad, en movimientos y agrupaciones sociales y a través de medios y tecnologías. La formación como humanización de los "no civilizados" está puesta en cuestión (Narodowoski, 1999; Sáenz, 2007; Rueda, 2012a).

De otro lado, las estructuras políticas y económicas ya no están organizadas siguiendo el modelo de la sociedad nacional, pues hoy vivimos en sociedades globales de poderes multilaterales apoyados en la expansión de los medios masivos y las tecnologías digitales. Al respecto, expresa Runge (2012, pp. 252-253):

Frente a este escenario pareciera que la educación poco a poco abandona unos ideales de perfectibilidad de la pedagogía moderna sustentados en el desarrollo de la razón y la naturaleza humana, con fundamento en las ciencias modernas y asume los ideales sustentados en el nuevo biopoder que entiende la "naturaleza humana" como potencia y capacidad para la superación de las limitaciones naturales, y como instancia de optimización, de maximización de la productividad, de uso eficiente. 
Este nuevo biopoder privilegia las capacidades de crear, imaginar y comunicar de los seres humanos, que se ensamblan de maneras paradójicas a las formas y tecnologías de producción y rentabilidad actuales. De ahí su carácter farmacológico: como remedio y potencialidad de despliegue humano y al tiempo como veneno, como empobrecimiento y amenaza del mismo.

Pero no se trata de una ruptura total con el proyecto moderno. Desde nuestro punto de vista las tecnologías digitales, por una parte, han producido una mayor diseminación y expansión del texto escrito y de los desarrollos de la ciencia en todos los campos de la vida cotidiana; de hecho, lo que hacemos la mayor parte del tiempo en diferentes dispositivos y espacios es leer y escribir textos (mensajes cortos o largos, superficiales o profundos, científicos, técnicos o de negocios, en papel o en superficies digitales). La escritura no tiende a desaparecer con la digitalización, como algunos profetizaron, sino a desplegarse de nuevas maneras, en interacción con otros lenguajes, pero paradójicamente también al ritmo de las industrias culturales y del software y del hardware. Esto se produce en medio de nuevos desarrollos de las ciencias y tecnologías, de prácticas subjetivas individuales y colectivas emergentes, de nuevas formas de subordinación y resistencia, sin las cuales no podrian funcionar tales tecnologías. Consideramos que esta conjunción de hechos complejos configura un proceso de poshumanización, para bien y para mal, un momento histórico que plantea los mayores retos y deudas con el proyecto de la formación y la pedagogía moderna, para retomarlo y deconstruirlo, en aras de obtener justicia, reconocimiento de la diferencia y acogida de los otros y lo otro. Asuntos caros a un nuevo proyecto de formación humana.

Por eso, un camino que hemos esbozado en otros lados (Rueda, 2007, 2012a) es entender las actuales tecnologías y el lenguaje de la hipertextualidad más que como una ruptura total como una continuación del proyecto cultural moderno de occidente ${ }^{3}$. Pero ello implica su deconstrucción y al tiempo su reinvención para pensar un nuevo

Ello debería incluir además una reflexión crítica sobre nuestra comprensión de las tecnologías, ligada a su caracterización histórica en occidente. Esta ha desconocido otras tecnologías y escrituras, las prehispánicas, por ejemplo. Para efectos de este artículo no podremos entrar en este debate; asunto que dejamos aquí en ciernes. 
humanismo. De esta manera, el giro visual ${ }^{4}$ y una oralidad secundaria, o escrituras visuales, parecen emerger en un proceso de pluralización de las formas de lectura, de las prácticas escriturales y de los tipos de textos en nuevos soportes. Pero también de las prácticas de socialización y formación. Nuestro interés aquí es destacar los modos de formación "informales" , que no pasan por la institución escolar ${ }^{6}, \mathrm{y}$ donde lo cognitivo se extiende a las dimensiones expresivas. Siguiendo a $\operatorname{Lash}^{7}$ (2002), las actuales escrituras visuales o hipermediales no pasan necesariamente por la reflexión consciente, racional, ni por la estabilidad del conocimiento, sino por formas pre-reflexivas, no conscientes y afectivas de reflexividad. Pero para comprender las maneras en que sujetos humanos se relacionan con las tecnologías, y cómo estas catalizan, posibilitan (y no determinan) procesos de subjetivación individual y colectiva, requerimos una ontología que nos permita ver su rol de agentes en este proceso de (pos)humanización de nuestras sociedades, pues de hecho, al lado de las transformaciones en la escritura del libro como dispositivo central de humanización en la pedagogía moderna, hay otra serie de tecnologías del lado de la digitalización, la genética y las tecnologías reproductivas que nos ubican en tiempos de poshumanismo ${ }^{8}$.

4 Nos referimos aquí al debate de la posmodernidad entre el sentido proveniente de un modelo racional y logocéntrico de la escritura vs. aquel originado en la emoción y los afectos que suscita la imagen.

5 Seguimos aquí el planteamiento de J. Trilla (1986), según el cual la educación informal es aquella que se produce mediante procesos educativamente indiferenciados de otros procesos sociales o inespecíficos, y en los que se aprenden valores, conocimientos y actitudes.

6 Los resultados de la investigación educativa en el campo de la Informática Educativa siguen siendo muy eufóricos y optimistas en los discursos y políticas, pero bastante ambiguos y poco contundentes en los estudios concretos. Luego de 15 años de incorporación de la informática educativa en los currículos escolares, no se ha logrado demostrar mejoras en los niveles de aprendizaje, ni en el rendimiento académico. Sin embargo, es cierto que en contextos de pobreza y de poco acceso a otros recursos culturales, la llegada de los computadores a ciertas comunidades ha significado no solo una enorme motivación, sino una posibilidad de acceso al conocimiento local y global. Pero insisto en que esto no significa que los computadores mejoren "per se" la educación o el aprendizaje, como lo anuncian las políticas educativas o las empresas de tecnologías y de software y hardware. Esta ideología felicista sobre los computadores no solo existe en Colombia, sino que es un fenómeno mundial.

7 Lash (2002) se refiere al obrar humano en tanto auto-regulación. La reflexividad la comprende no como un estado o esencia, sino como un proceso que emerge tanto de nuevos procesos de individuación, como de estructuras de comunicación e información. Mientras Giddens y Beck (1997) priorizan una reflexividad del saber de tipo cognitiva, Lash plantea la reflexividad estética o expresiva, que no es conceptual sino mimética, y ofrece una comprensión de sí y de las prácticas sociales implícitas. Así, los modelos de subjetividad a los que conduce este tipo de reflexividad se basan en el deseo, la imaginación creadora, los afectos y el placer.

8 El tema del humanismo abarca muchas más problemáticas que no son nuestro objetivo, pues aquí nos convoca la pregunta por la formación. No obstante, es evidente que asuntos relacionados con los desarrollos de la genética, la nanotecnología, la biotecnología, las tecnologías reproductivas tienen que ver con la intervención sobre la "naturaleza humana" y que muchos autores catalogan como la muerte del humanismo. En lo que quisiéramos insistir en relación a las actuales transformaciones catalizadas por las tecnologías de la información y la comunicación es que ya no es suficiente un humanismo del individuo, pues este deviene sujeto de manera relacional en diversas interacciones con 


\section{Los estudios sociales de la ciencia y la tecnologia y de cultura material}

Desde los estudios sociales de la ciencia y la tecnología, autores como Latour $(1987,2007)$, Doménech y Tirado (1998) y Haraway (1991 / 1995) plantean una ontología que supera las fronteras del humanismo y les otorga a los objetos una agencia simétrica. También desde los estudios de cultura material se propone analizar la vida humana como una interacción incesante y variada entre gente y miles de cosas variadas (Miller, 1987; Schiffer, 1999; Olsen, 2003; Ingold, 2011). Todos estos autores nos plantean la necesidad de comprender cómo los objetos, las tecnologias, con-forman seres humanos, sus experiencias, actitudes, pensamientos y acciones, y cómo estos, a su vez, las trans-forman. Es decir, se trata de una ontología que se opone a la tradición humanista antropocéntrica, dualista y racional, y que abre las fronteras entre los seres humanos, el medio, los animales y objetos. De esta manera asuntos como el actual biopoder, el cambio climático, la investigación genética, la geoingeniería, las tecnologias digitales, la nanotecnología, son muestras de un poshumanismo que requiere abordajes transdisciplinares y complejos (Braidotti, 2013/2015).

Desde este marco, destacamos tres implicaciones para nuestros estudios (Rueda, 2012b, 2014): primero, la importancia de reconocer que la producción de subjetividad individual y colectiva está entretejida con un entorno material, hoy provisto de manera dominante -pero no exclusiva- por la expansión de tecnologías de la información y la comunicación que se diseminan bajo una ideología del desarrollo, el progreso y la felicidad. Los procesos de subjetivación entonces son entendidos como procesos relacionales y en diversas interacciones con "otros" diferentes. Dos, el carácter farmacológico de tales tecnologias en las sociedades actuales que, por una parte, como remedio, favorecen un proceso de intensificación de la individuación, de las formas de experiencia y de democratización de la información y el conocimiento (que inició con el humanismo moderno, la imprenta y la masificación de la alfabetización); pero que, de otra parte, son un veneno, pues

otros y a través de una "socialidad plataformada", que lo lanzan a nuevas formas posibles de ser, pero esto se produce en medio de una colonización de la vida por parte de los mercados y su lógica de rentabilidad y consumo. 
producen también formas de sujeción (o desindividuación) novedosas por su articulación con procesos de mercantilización y de las industrias culturales (Stiegler, 2009). Tres, estas tecnologías son un dispositivo de la forma de poder contemporánea, que captura nuestros conocimientos, nuestra atención, deseos y sueños a través de dispositivos programables, en medio de una lógica de la inmediatez, del consumo y la conectividad que prescinde de inventarse maneras de reflexión y crítica sobre las formas de vida que construimos con ellas. Pero al mismo tiempo, a través de estas tecnologías sujetos individuales y colectivos inventan formas de resistencia y creatividad social que buscan resignificar y reorientar, a nivel micro, cotidiano y global, la tendencia dominante del actual capitalismo informacional. Esto es, el poshumanismo toma forma a partir de desarrollos científicos y tecnológicos, así como de prácticas sociales paradójicas y ambiguas, que nos ofrecen muchas posibilidades, pero también amenazas.

\section{Las formas de socialidad mediatizada y la formación informal}

Principalmente uso Facebook para mantenerme conectado con el mundo y ver en qué andan las personas más cercanas a mí... Me tomo fotos porque es un modo de llevar un registro sobre etapas de mi vida e intereses personales.

(Informe Etnográfico, entrevista a EC, 2013)

Soy plenamente consciente de que la información que compartes por estas redes es vulnerable, o al menos te hace vulnerable. Pero... ¿Qué pasaría si no existiera esta red (Facebook)? Me pregunto si mi grupo de amigos sabría lo que pienso acerca de muchas cosas. O tal vez no sabrian de qué hablarme cuando estemos en contacto... Esto no es malo, pero al mismo tiempo, haría de la socialización un proceso más lento.

(Informe Etnográfico, Entrevista a MP, 2013) 
[...] Facebook es como el cerebro; aquí es donde pruebo ideas, contrasto, rebusco imágenes, investigo la vida, la vivo y me ayudo con lo que voy creando con todas estas ideas.

(Informe Etnográfico, Entrevista a IB, 2013)

Guardar estos registros del yo en una suerte de askesis (consideración progresiva del yo), en una oralidad secundaria, parece retomar esa ética del yo de la que hablaba Foucault (1990) a propósito de la escritura de los diarios íntimos. Pero ya no es una práctica solitaria, racional como vía de perfeccionamiento, como lo supusieron el humanismo y la pedagogía moderna; por el contrario, estas escrituras se insertan en nuevas prácticas afectivas, sociales y culturales vinculadas a plataformas tecnológicas de comunicación. Estar conectados con el mundo de hoy, comunicarse y "ver" a las personas que se quiere y compartir la vida son las principales razones que aluden quienes usan intensivamente las redes sociales digitales como Facebook. Se trata de escrituras íntimas públicas que son almacenadas en estas plataformas. Estas son un nuevo diario intimo, ahora digital, pero que no controlamos totalmente. Así, los sujetos experimentan una cierta (in) consciencia sobre la vulnerabilidad a la que se exponen y un deseo de registrar, como en los antiguos diarios escritos, el acontecer cotidiano. Pero se trata de una escritura configurada por una agencia maquínica que nos convoca, a través de diversos mecanismos, a interactuar permanentemente (actualizar nuestro estado, dar "me gusta", saber en qué andan los amigos, etc.), tomar parte de un amplio y variado repertorio de sitios web y aplicaciones multimedia, donde otros pueden aportar a la producción de los perfiles individuales. Así, estas redes se mantienen y amplian gracias a una permanente e intensa actividad de intercambio social con otras personas dentro y fuera de ellas, y a diferencia de la interacción cara a cara, siempre se dejan huellas de tales interacciones, siempre es posible volver a ellas o que "alguien" o "algo" las siga. Es una socialización a través de un gran dispositivo de escritura y de memoria que no controlamos totalmente. De ahí su potencia y mayor peligro como dispositivo de creación colectiva y de vigilancia. Estamos pues hablando de tiempos de poshumanismo. 
En un estudio que realizamos sobre la red social Facebook entre 2012 y 2013, observamos las formas de presentación de sí en dicha red social ${ }^{9}$. La investigación consideró, en una primera fase sobre la cual no hablaremos en este texto (véase Rueda y Giraldo, 2016), el inventario y clasificación de 7.200 imágenes de perfiles de Facebook. En la segunda fase, realizamos un seguimiento intensivo de las trayectorias de los perfiles de 12 personas en dicha red $^{10}$, a través de una etnografia virtual y de entrevistas mensuales. La selección de este grupo se basó, fundamentalmente, en que sus páginas de Facebook estuvieran abiertas al público, en que mostraran una actividad alta en el mantenimiento de la misma y, sobre todo, en estos dos puntos: que nos autorizaran a realizar la observación de sus perfiles durante seis meses y que estuvieran dispuestos a participar en entrevistas. Este seguimiento se apoyó en una guía de observación semanal y de fines de semana y en la realización de entrevistas quincenales (presenciales o vía videoconferencia). En dichas entrevistas, conversamos sobre los registros hechos en nuestros diarios de campo (junto con capturas de pantalla de las observaciones) para aclarar los sentidos de la actividad que llevaron a cabo en Facebook durante dicho periodo de tiempo. De esta manera se realizó un proceso en espiral donde cada observación nos llevó a nuevas preguntas sobre los procesos de subjetivación, las cuales abordamos en las entrevistas y estas a su vez nos permitieron ir focalizando las observaciones. Esta etnografia además nos permitió aproximarnos a una comprensión tanto de las relaciones entre las dinámicas de presentación de la persona online-offline, así como de la ecología de piezas -verbales, gráficas, audiovisuales- (Gómez et al., 2012).

9 El estudio "Formas de presentación de la persona en la red social Facebook" (2011-2013), fue un proyecto formulado desde la Universidad del Valle y contó con la cooperación interinstitucional de la Universidad Pedagógica Nacional y la Universidad ICESI. En este equipo participaron como investigadores: Rocío Gómez, Diana Giraldo, Julián González, Viviám Unás, Armando Henao y Rocío Rueda Ortiz. Como monitores y colaboradores: Ana Paola Angulo, Natalia Cárdenas, Maryoli Ceballos, Mónica López, Juan Carlos Mora, Laura Parra, Jhony Velasco y Jonn Velasco (Gómez et al., 2013).

${ }^{10}$ El grupo de sujetos estuvo compuesto por cinco mujeres y siete hombres, distribuidos así: ocho entre los 20 y los 30 años de edad (cuatro mujeres y cuatro hombres, el grupo más joven del estudio); dos hombres entre los 30 y 50 (el grupo de adultos) y una mujer de 70 años. La mayoría de personas del grupo (ocho personas) pertenece a una generación joven "universitaria" de clase media de la ciudad de Cali. Los dos hombres adultos trabajan en los campos de la comunicación y el turismo, respectivamente, y la adulta mayor está pensionada. 
Encontramos que, para todos los sujetos que participaron en el estudio, la amistad es fundamental en su actual experiencia con los nuevos repertorios tecnológicos y en particular con Facebook. Si 'humanitas' implica la "amistad del hombre con el hombre", este entorno puede verse como un enorme espacio de humanización. Sin distinción de generación, edad, género, trabajo o estudios, para cada uno/a el mundo de los lazos filiales, de la amistad, está justo en el centro de sus interacciones en Facebook. No obstante, fue evidente que en las personas más jóvenes la intensidad (en tiempo y cantidad de interacciones) con que se vive la socialización a través de la red social es mayor que la de las personas adultas. Como dice la joven de la entrevista al inicio de este apartado, para ella, si no existieran las redes sociales "el proceso de socialización sería más lento". En efecto, lo que vemos es que las actuales tecnologias introducen una aceleración en la experiencia de socialización. Dicha aceleración se produce por una suerte de "aligeramiento" o "facilitación" de las prácticas sociales comunicativas en la cotidianidad que ofrece el actual ecosistema tecnológico: internet, celulares, redes sociales digitales, programas de edición de imagen, video y audio, entre otros. Así, en los procesos de subjetivación participan otros sujetos, pero también software, protocolos de programación, hardware y otras tecnologías. A este respecto, dos de los entrevistados, señalaron: "Actualmente, mi disposición de ser registrado por la cámara, en el caso del Facebook, para mí es una forma de mercadeo, una forma de venderse a una sociedad. [...] Es una puerta para venderse a la gente, es una ventana de cómo sos vos y como te mostrás" (Informe Etnográfico, entrevista a AR, 2013, febrero). “[...] con el paso del tiempo comenzó a concebir la plataforma como una tribuna en la que puede comunicar sus ideas e intentar movilizar a sus contactos en torno a sus proyectos y posturas ideológicas. Sus obras pasaron de estar amarradas a las industrias culturales y comenzaron a hilarse con sus propósitos laborales y su deseo de resistencia" (Informe Etnográfico, entrevista a MM, 2013, mayo).

Estos intercambios entre humanos y no humanos son catalizados por un sistema tecnológico automatizado en una lógica social (Van Dijck y Poell, 2013). Dicha lógica se refiere a los procesos, principios y prácticas mediante los cuales estas plataformas procesan 
la información y la comunicación y cómo "canalizan" y con-forman la interacción social de una manera que parece transparente, neutral y estandarizada, bajo algoritmos y scripts informáticos. Así, la formación no es un asunto solo de humanos. Los agentes no humanos al configurar tales interacciones también nos "co-forman". Esta es una de las condiciones del actual poshumanismo.

Las personas que participaron en el estudio coinciden en señalar que al principio usaron Facebook sin prestarle mucha atención a las implicaciones de "subir todo" a la red social; además añaden que aceptaban a todos los contactos sugeridos por la plataforma ("X es amigo de $Y$ ", "Z quiere conocerte"). Pero con el paso del tiempo y al ver las continuidades entre el mundo off y online y tener mayor dominio técnico del funcionamiento de la plataforma, estos empezaron a usar filtros y a actuar más reflexivamente en la misma. Incluso, como señala uno de los sujetos, se es consciente de que hay una lógica de mercado detrás de la plataforma; algunos la rechazan, en tanto que otros la asumen y juegan con ella.

De esta manera, la agencia de redes sociales como Facebook se caracteriza porque las formas de construir lo social pasan por procesos de "clasificar", "etiquetar", "compartir", "recomendar" y "relacionar amigos" (o "la gente que usted puede conocer"), a través de un script informático que "sugiere" relaciones sociales a partir de datos inferidos. Se trata de diversos mecanismos de co-formación de los procesos de socialización. Un mecanismo es el de programabilidad (Van Dijck y Poell, 2013), para desencadenar y dirigir las contribuciones creativas o comunicativas de los usuarios. No obstante, los sujetos que observamos no solo contribuyen a alimentarlas, sino también a crear resistencia a las estrategias de mercado y a las instrucciones codificadas o a los protocolos de estas plataformas. Así, por ejemplo, frente a la noticia sobre la venta de información de los usuarios a terceros por parte de Facebook, muchas personas organizaron protestas en la misma red, bloquearon protocolos y obligaron a ajustar las políticas de privacidad. Otros nos mencionaron que no querian sentirse bajo presión y que por eso decidieron cerrar por un tiempo sus páginas. Facebook, entonces, no es totalmente autónomo, pues tiene 
que complacer tanto a sus millones de usuarios como a sus anunciantes. Aquí surgió un ejercicio de reflexividad colectiva que se difundió con argumentos y emociones compartidas: "defendemos los derechos nuestros y los de nuestros amigos". Esto, sin embargo, no significa que las interacciones en esta plataforma siempre tengan este carácter reflexivo. Como se mencionó antes, los sujetos se aproximan casi que jugando para estar con otros amigos; hay una dimensión afectiva muy fuerte y por el camino van aprendiendo y ajustando sus actuaciones en la misma.

Uno de los hallazgos en relación con las imágenes de perfil, como primer paso de presentación en esta red social, es que existe cierta homogenización. En la mayoría de fotos, las personas tienen las mismas poses, expresiones, sonrisas (planos picados, imitaciones de gestos o de formas de vestir de artistas famosos, por ejemplo). En otros casos hay una labor expresiva de pre y posproducción de las imágenes. En todos los casos, no obstante, vimos una gran influencia de los medios e industrias culturales. Aquí aparece un mecanismo de popularidad (Van Dijck y Poell, 2013) que no nació en Facebook propiamente, sino que proviene de los medios masivos y tiene un enorme poder para crear personalidades mediáticas. Se trata además de una visualidad dominante, con unos valores de una sociedad de consumo que exige "estar feliz", estar "conectados" y ser parte de rankings de popularidad (más amigos, más votos, etc.). De hecho, los algoritmos del dispositivo "me gusta" de Facebook automáticamente seleccionan evaluaciones emotivas y positivas de ciertos temas (extendiéndose a otros medios masivos) y se evaden la crítica o las posiciones contrarias. Sin embargo, en nuestro estudio encontramos que algunos jóvenes usan la plataforma de Facebook también con objetivos comerciales y sociales. Desde vender obras, productos y ofrecer servicios, hasta promover causas por el medio ambiente o por la no violencia contra la mujer. Los indices de popularidad pueden ser muy útiles para dichos objetivos. Aquí la crítica de Van Dijck y Poell requiere ser mirada también desde otra perspectiva, porque estas redes de consumo popular no están "per se" "vendidas" al mercado, sino que catalizan procesos de identificación de los más jóvenes y procesos de acción ciudadana. 
Como se lee en una de las entrevistas (Informe Etnográfico, entrevista a DJ, 2012, febrero):

[...] Se trata de los "ritmos" que les imponen las redes sociales a tus rutinas de vida. Suele ocurrir que cuando uno está concentrado revisando las notificaciones de los contactos, en el momento menos pensado ya han pasado una o dos horas. Y, claro, estos "ritmos" se potencian con las nuevas modificaciones que se le implantan a la plataforma. Una de ellas es la barra superior derecha que está contando, en tiempo real, las acciones que realizan nuestros "amigos": comentar fotos, dar "me gusta", aceptar solicitudes de amistad. Si nos dedicamos solo a ver esa barra, nos daremos cuenta de la cantidad de eventos online que pueden pasar en un minuto.

La conectividad propia de estas redes es otro mecanismo que no tiene que ver solo con la conexión de individuos, sino que enfatiza la conformación mutua de usuarios, plataformas y anunciantes, así como la "actuación" o performance en el ambiente online. De este modo, al lado de la programabilidad y de la popularidad, la conectividad representa una estrategia que posibilita una conexión entre humanos, impensable hace unos años y, al mismo tiempo, una fuerza "artificial" que surge a través de una conectividad automática (Stiegler, 2013). Pero esta conectividad consume tiempo y atención, como lo expresa el joven de la entrevista; e incluso genera una sensación de angustia dado que no es posible mantenerse "al dia" con todas las notificaciones que la plataforma envía constantemente y que permiten estar "conectados".

No obstante, la conectividad, como lo hemos visto de la mano de movimientos y colectivos sociales (Rueda, Fonseca y Ramírez, 2013), pero también de la mano de individuos comunes como los que participaron en nuestro estudio -interesados en temas sociales como la equidad de géneros, el cuidado del medio ambiente y de los animales-, favorecen procesos de participación política desde abajo. Así, la agencia de las tecnologías también es afectada por la agencia de los sujetos. A este respecto uno de los entrevistados, señaló (Informe Etnográfico, entrevista a MM, 2013, mayo): 
A mí me gusta mucho esa foto (de su perfil en Facebook) porque, además de que aprecio mucho a mi amiga y de que salimos medio boniticos, representa la diversidad como tal y hace una evocación al respeto, la solidaridad y el afecto entre diferentes, muy a propósito de la conmemoración del día mundial contra la homofobia el martes pasado. [...] Fue muy bonito sentir la solidaridad de tantas personas... creo que muchas cosas están cambiando, afortunadamente.

Temas como la homofobia y la violencia contra las mujeres aparecieron durante varias semanas tanto en los perfiles de Facebook de algunos jóvenes, como en los noticieros de televisión. Esta conectividad no se restringe a los nuevos medios digitales, sino que integra los medios masivos. Así, observamos otro mecanismo: la "dataficación" (Van Dijck y Poell, 2013). Esta consiste en el tratamiento de datos en "tiempo real" para calificar, sondear, evaluar e incluir las respuestas de los usuarios dentro de la arquitectura de las plataformas. De ahí que Facebook haga seguimiento del "tráfico social" en la plataforma en relación con indicadores de temas de moda, palabras claves, tendencias, sentimientos, puntos de vista, así como los ítems que son compartidos con mayor frecuencia y los que más han gustado. Esta condición se traslapa con aquella que conocemos de los medios masivos como transmisiones "en vivo". De esta manera, estas interfaces en tiempo real dan poder a los usuarios en formas complejas, pues, por una parte, favorecen la acción personal, la libertad de expresión, las formas de política desde abajo como la política cultural por la equidad de géneros y, por otra, tales plataformas orientan y explotan las actividades de los usuarios, según los intereses corporativos subyacentes.

En consecuencia, vemos que los procesos de socialización en estos entornos digitales son una coproducción en la que se cruzan las estrategias de la plataforma y las tácticas de los usuarios (Cardon, 2008). Se trata de una socialización con-formada por agentes humanos y no humanos, a través de mecanismos como los de programabilidad, conectividad, popularidad, dataficación, alimentados por la actividad constante y permanente de millones de usuarios, instituciones, anunciantes y empresas, así como por diversos programas de software. Los procesos de formación informales tienen aquí un contexto paradójico, 
pues nuestra atención psíquica y social está distribuida en diversas redes y escenarios que abren muchas posibilidades de expresión individual y colectiva, pero a pesar de contar con un dispositivo escritural que virtualmente posibilita el diálogo, su lógica del corto plazo, la hiperabundancia de información y comunicaciones, su fluidez y velocidad, reduce los tiempos de reflexión (Rueda, 2012b). Esto es, el proyecto del humanismo es llevado a sus límites, y al tiempo el poshumanismo cae en la paradoja de estar atado a un biopoder que recupera la "diferencia del otro", para vincularlo a un modo de vida que celebra el éxito, la rentabilidad, la competitividad y el consumo.

El individualismo y la autonomía han llegado a un punto en el que debemos reflexionar sobre nuestra libertad y capacidad de elección. Pero no es una alerta catastrofista, pues no podemos dejar de reconocer que también los sujetos, informalmente y a partir de la propia experiencia, van ajustando las maneras como se relacionan con estas tecnologías y van inventando otros usos y producciones que no responden necesariamente a esa lógica de mercado y de utilidad. Esta lógica social de las plataformas como Facebook aún puede redireccionarse. Sin embargo, esto no se produce necesariamente de manera consciente y reflexiva, a veces sigue vías miméticas, pre-reflexivas.

Por eso es importante ser conscientes de que la conectividad tan aclamada de estas tecnologías como símbolo de una nueva inteligencia colectiva no implica necesariamente colectividad ni sociedades justas y equitativas. Para ello se requiere el reconocimiento de la diferencia, la solidaridad, el trabajo cooperativo. La experiencia de movimientos sociales y colectivos de activistas en la red, de colaboratorios y de muchos otros experimentos sociales con estas tecnologías han mostrado que son también espacios para compartir formas alternativas de artesania que desconfian de las soluciones rápidas, de la urgencia de lo "útil y rentable" y que proponen una acción creadora y no mecánica a través del trabajo cooperativo y solidario (Sennett, 2008/2009). 
En esas experiencias colectivas, pero también en otras experiencias individuales de sujetos que buscan transformar su cotidianidad tenemos esperanza, creemos que somos sujetos prometedores ${ }^{11}$.

\section{La formación como artesanía en tiempos de (pos)humanismo}

Como señala Sáenz (2007), hay un cierto consenso académico e institucional en torno a la idea de que ya no son las fuerzas escolares las que están construyendo de manera más eficaz las formas de sentir, de desear, de valorar y de poder; sino que están resultando más efectivas las maneras informales de niños y jóvenes de relacionarse, con altos grados de autonomía, con los medios masivos de comunicación, el computador, el grupo barrial, los productos de las industrias culturales y con formas artísticas y de comunicación. Entonces, ¿cómo entender los procesos de formación en tiempos más allá del humanismo de la escuela y cómo tener esperanza en sujetos prometedores?

Pues bien, hemos destacado algunos mecanismos de co-formación desde la plataforma de Facebook, ahora queremos resaltar la agencia de los sujetos. En nuestro estudio consideramos el trabajo que los sujetos realizan en dicha red como una artesanía. Esta "como técnica se refiere tanto al deseo como a la habilidad para realizar bien un trabajo" (Sennett, 2008/2009, 2012); por eso también es una técnica del yo, pues cuando trabajamos en algo, hay procesos de pensamiento y sentimientos que se producen simultáneamente. La artesanía es un tipo de saber que ha configurado desde siempre unas formas de experiencia, de acción y de comunicación en el mundo cotidiano, que hoy también podemos observar en las actuales formas de vida tecnológicas. Estas prácticas artesanales aparecen como una manera de deconstruir ese humanismo de la razón y de las ciencias que ha desconocido las emociones y otros saberes. En nuestro estudio hablamos de

\footnotetext{
11 O tal vez podemos hablar con Broncano (2009) del humanismo ciborg, en el que la tecnología es la producción de seres que son también producto de la tecnología: los humanos. Monstruos de la naturaleza, aunque monstruos prometedores.
} 
artistas mundanos ${ }^{12}$ que producen obras "menores", "in-útiles", a las que dedican tiempo para llenar de sentido su cotidianidad, para sentirse "parte de", a través de imágenes, textos, música en sus páginas de Facebook y que, en el caso de los más jóvenes, hace además parte de su exploración identitaria. Trabajo inútil que resiste al biopoder que nos pide ser productivos. Es además la posibilidad de sentirse responsable del "hacer", capacidad que hemos perdido, como señalan Crawford y Chabot (Revista Philosophie, 2015) en la entrevista realizada por la Revista de Filosofia, pues en la actual sociedad de consumo perdemos el horizonte de nuestra capacidad de acción sobre el mundo, no nos sentimos responsables de este. El trabajo artesanal es entonces una vía para mantenernos a nosotros mismos enraizados en la realidad material (Sennett, 2012) y de asumir una política ante el mundo.

De hecho, como los artesanos que describe Sennett, los jóvenes que observamos dedican bastante tiempo a la imitación, a la atención en los detalles, hasta ir encontrando la forma singular de artesanía de su propia imagen. Esto se produce en tiempos de trabajo individual como en tiempos de trabajo colaborativo, de atención compartida y de empatía, en los que los amigos aportan a esa construcción de la imagen de sí de otros. De esta manera, cotidianidad, identidad y tecnologías son mutuamente constituidas a través de un proceso continuo de artesanía (Rueda y Giraldo, 2016).

En este hacer, la cooperación es un elemento clave, pero igualmente un proceso espinoso, lleno de dificultades y ambigüedades. Esta requiere ser desarrollada y profundizada, especialmente cuando tratamos con gente diferente a nosotros mismos, porque con ellos la cooperación exige mayor esfuerzo. Lo que observamos en estos artistas mundanos es que se apropian de estas tecnologias, a través de aprendizajes informales: son aprendizajes situados, auto-didactas, en el que más que explicaciones verbales sobre cómo usar estas plataformas, se

\footnotetext{
12 Siguiendo a Gómez et al. (2012): "llamamos artistas a estos sujetos que transforman objetos no digitales/no electrónicos (analógicos) en bienes digitales-electrónicos disponibles para internet. Esas "opera" consisten en "dejarse fotografiar" o "escribir un texto" o "bajar un archivo digital" (imagen, por ejemplo) y relocalizarlo en otro lado o editar e intervenir una pieza digitalizada y electrónica, provenga o no de internet. Es decir, aunque en una operación típica de cooptación y expropiación de riqueza socialmente gestionada, nos han hecho creer que la fuerza de Facebook está en su maquinaria técnica, realmente el valor y riqueza está en que hay miles de millones de seres humanos que pueden hacer obras y acciones on y off line a partir de lo que hay allí” (p. 7).
} 
aprende "in situ", imitando, estando dentro, jugando ${ }^{13}$. Ello implica ser paciente, desarrollar habilidades para "observar", leer y reelerse en el contexto de muchos mensajes, e imitar a otros hasta encontrar el "estilo" propio y poderse comunicar. Se requiere además desarrollar cierta empatía para comprender cómo otros resuelven dificultades en dichos entornos. Estos intercambios hacen a las personas más conscientes de los otros, pero también de las propias ideas y de las implicaciones de sus acciones. Este proceso de tejer juntos, dice Sennett siguiendo a Bakthin, implica intercambios divergentes y no siempre un consenso. De hecho, Facebook es un escenario en potencia de comunicación, pero termina muchas veces siendo un espacio para "ratificar" una posición, la que se parece a lo que "yo" pienso (me gusta), y por tanto se refuerza la transmisión de datos, de información y no una comunicación dialógica. Esta requiere mucho trabajo, atención y cuidado del otro.

Por lo tanto, consideramos que el poshumanismo no tiene que ver con una idea más "desarrollada" de lo humano, ni con una etapa posterior, sino con una ontología relacional con el mundo, que deviene del encuentro con los otros y "lo otro" (la naturaleza, los animales, los objetos); en donde lo humano se constituye relacionalmente con otros humanos y no humanos, en un mundo material para devenir nos-otros. La formación entonces pasa a veces por una reflexividad cognitiva como la que aprendimos del proyecto moderno y de la escritura del texto impreso, pero también por una reflexividad expresiva, empática, informal, desde la cual configuramos formas de ver el mundo y de actuar en él, como la que observamos en la plataforma de la red social Facebook. No obstante, se trata de procesos de subjetivación complejos y paradójicos, porque están amarrados a una forma contemporánea de biopoder y de protocolización de la vida social, de cuantificación y mercantilización de las industrias culturales.

Frente a ello planteamos la cooperación como una artesanía-tecnología del yo que nos permite actuar reconociendo la diferencia. Esta nos invita a que les demos fuerza a nociones como las que el

${ }^{13}$ Esto también se ha encontrado en los estudios sobre videojuegos. Al respecto hay dos tesis doctorales recientes muy interesantes, véanse: González (2013) y Cabra (2015). 
colombiano Orlando Fals Borda construyera en su trabajo sobre las costas colombianas, y volvamos a los "sentipensamientos" y a todos esos "saberes menores", "saberes invisibles", saberes vinculados al cuidado de los otros, que las feministas nos reclaman, como lo es también el trabajo pedagógico.

\section{Conclusión}

En el presente texto hemos destacado cómo la formación en tanto Bildung tiene que ver con la apropiación de los códigos de la cultura escrita. Con las actuales tecnologías se expande y disemina este proyecto humanizador a través de escrituras visuales, hipermediales, que operan ya no por vía de una racionalidad cognitiva reflexiva, sino a través de la mímesis y de la afectividad. Estas escrituras se convierten en una forma de experiencia de sí, de ética del yo, en un espacio de formación "informal", donde aparece una reflexividad que no es necesariamente crítica en primera instancia, sino que es pre-reflexiva. Así mismo, describimos nuevas formas de socialización y de co-formación a través de una "socialidad plataformada" (Van Dijck, 2012; Van Dijck y Poell, 2013) de las actuales redes sociales digitales. Alli se describieron cuatro mecanismos característicos: la programabilidad, la conectividad, la dataficación y la popularidad, en los que se con-forma la agencia de sujetos humanos y no humanos. También se destacó el carácter farmacológico de ese encuentro sociotécnico por su vinculación con la lógica de consumo de un capitalismo informacional que supone sujetos autónomos y emprendedores; valores que hoy se nos presentan ambiguos en un espacio urbano de consumo en expansión del que, como ya lo señaló Benjamin (1973), emerge un nuevo sujeto flâneur junto a una lógica de mercado y a la industria del entretenimiento.

En la formación como ámbito que se orienta tanto al sujeto (en lo que puede y quiere llegar a ser) como a la cultura (su reproducción y transformación), vemos que la manera como hoy confluyen prácticas provenientes de las tecnologías de la escritura del libro y de 
las escrituras visuales e hipermediales a través del actual ecosistema tecnológico, es un reto y una oportunidad para reconocer nuevas dimensiones expresivas, afectivas y estéticas que acompañan a estas nuevas escrituras y su potencia como artesanía del yo y del cuidado del mundo que habitamos. Pero al mismo tiempo nos alerta de la manera paradójica (farmacológica) en que estas nuevas escrituras se articulan con el nuevo biopoder, así como a una uniformización de la cultura a través del consumo, como una de las marcas de los tiempos actuales de poshumanismo. De ahí la importancia de una artesanía que nos ayude a hacernos responsables de nuestras acciones, y a reflexionar individual y colectivamente acerca de hasta dónde debemos cambiar nuestros estilos y formas de vida (Sloterdijk, 2009; Chul-Han, 2014) como una de las tareas más urgentes que tenemos en las ciencias sociales críticas contemporáneas y en particular en la pedagogía como medio de la cultura en tiempos de poshumanismo.

\section{Referencias}

Benjamin, W. (1973). La obra de arte en la época de su reproductibilidad técnica [J. Aguirre, Trad.]. Madrid: Taurus.

Braidotti, R. (2013/2015). Lo posthumano [J. C. Gentile, Trad.]. Madrid: Gedisa.

Briggs, A. y Burke, P. (2002). De Gutenberg a Internet. Madrid: Taurus.

Broncano, F. (2009). La melancolia del ciborg. Barcelona: Herder.

Cabra, N. (2015). Cacharreo o aprendizaje salvaje en videojuegos (Tesis Doctoral en Antropología). Universidad de los Andes, Bogotá.

Cardon, D. (2008). Le design de la visibilité: Un essai de cartographie du web 2.0. Réseaux, 6(152), 93-137.

Chul-Han, B. (2014). Psychopolitik. Neoliberalismus und die neuen Machttechniken. Frankfurt: Fischer-Wissenschaft. 
Doménech, M. y Tirado, J. (1998). Sociología simétrica: ensayos sobre ciencia, tecnología y sociedad. Barcelona: Gedisa.

Foucault, M. (1990). Las tecnologías del yo. Barcelona: Paidós.

Giddens A., Beck, U. y Lash, S. (1997). Modernización Reflexiva. Politica, tradición y estética en el orden social moderno. Madrid: Alianza Editorial.

Gómez, R. et al. (2012). Rutas y configuraciones de la imagen de perfil en Facebook (Documento interno de trabajo). Universidad del Valle, Cali.

Gómez, R. et al. (2013). Formas de presentación de la persona en Facebook (Informe final de investigación). Universidad del Valle, Cali.

González, J. (2013). Niños que videojuegan juegos que estructuran tiempos (Tesis Doctoral). Programa de Doctorado en Psicología, Universidad del Valle, Cali.

Haraway, D. (1991/1995). Ciencia, cyborgs y mujeres. La reinvención de la naturaleza [M. Talens, Trad.]. Madrid: Cátedra - Instituto de la Mujer, Universitat de València.

Ingold, T. (2011). Essays on movement, knowledge and description. London New York: Routladge.

Lash, S. (2002). Critica de la información. Buenos Aires: Amorrortu.

Latour, B. (1987). Ciencia en acción: cómo seguir a los científicos e ingenieros a través de la sociedad. Barcelona: Editorial Labor.

Latour, B. (2007). Nunca fuimos modernos. Ensayo de antropología simétrica. Buenos Aires: Siglo XXI.

Miller, D. (1987). Material Culture and Mass Consumption. Oxford: Blackwell.

Narodowski, M. (1999). Después de clase. Desencantos y desafios de la escuela actual. Buenos Aires: Novedades Educativas. 
Olsen, B. (2003). Material culture after text: re-membering things. Norwegian Archaeological Review, 36(2), 87-104.

Revista Philosophie. (2015). Macht euch die Hände Schmutzig! Entrevista a Pascal Chabot y a Matthew Crawford. Revista Philosophie, 5, 58-61.

Rueda-Ortiz, R. (2007). Para una pedagogía del hipertexto: una teoría entre la deconstrucción y la complejidad. Barcelona: Anthropos.

Rueda-Ortiz, R. (2012a). Educación y cibercultura: retos para (re)pensar la escuela hoy. Revista Educación y Pedagogia, 24(62), 157-171.

Rueda-Ortiz, R. (2012b). Sociedades de la información y el conocimiento: Tecnicidad, Pharmakon e invención social. Nómadas, 36, 43-55.

Rueda-Ortiz, R. (2014). (Trans)formación sociotécnica, subjetividad y política. Pedagogía y Saberes, 40, 11-21.

Rueda-Ortiz, R., Fonseca, A. y Ramirez, L. (Eds.). (2013). Ciberciudadanías, cultura politica y creatividad social. Bogotá: Universidad Pedagógica Nacional.

Rueda, R. y Giraldo, D. (2016). La imagen de perfil en Facebook: identidad y representación en esta red social. Folios, 43, 119-135.

Runge, A. (2012). La educación como una antropotécnica contra el salvajismo humano: paradojas y complicaciones para el pensar pedagógico moderno. Revista Educación y Pedagogía, 24(62), 247-265.

Sáenz, A. (2007). La escuela como dispositivo estético. En G. Frigeiro y G. Dicker (Comps.), Educar: (sobre)impresiones estéticas. Buenos Aires: Del Estante Editorial.

Schiffer, M. (1999). The Material Life of Human Beings. Artifacts, Behavior, and Communication. London - New York: Routledge.

Sennett, R. (2008/2009). El artesano [M. A. Galmarini, Trad.]. Barcelona: Anagrama. 
Sennett, R. (2012). Together. The rituals, pleasures and politics of cooperation. USA: Yale University Press.

Sloterdijk, P. (2000). Normas para el parque humano [T. Rocha Barco, Trad.]. Madrid: Ediciones Siruela.

Sloterdijk, P. (2009). Du musst dein Leben ändern. Über Anthropotechnik. Frankfurt: Suhrkamp.

Stiegler, B. (2009). Von der Biopolitik zur Psychomacht. Frankfurt: Suhrkamp.

Stiegler, B. (2013). The most precious good in the era of social technologies. En G. Lovink y M. Rasch (Eds.), Unlike Us Reader. Social Media Monopolies and their Alternatives (pp. 16-30). Amsterdam: Institute of Network Cultures.

Sting, S. (1998). Die Schriftlichkeit der Bildung. Medienimplikationen in Bildungsdenken von Herbart und Schleiermacher. Zeitschrift für Erziehungswissenschaft, 1, 45-60.

Trilla, J. (1986). La educación informal. Barcelona: Ariel.

Van Dijck, J. (2012). The culture of connectivity. A critical history of social media. New York: Oxford University Press.

Van Dijck, J. y Poell, T. (2013). Underestanding social media logic. Media and Communication, 1, 2-14.

\section{Cómo citar este artículo}

Rueda Ortiz, R. (2017). Subjetividad y tecnologías de la escritura. La formación en tiempos de poshumanismo. Universitas Humanística, 83, 133-155. http:// dx.doi.org/10.11144/Javeriana.uh83.stef 